\title{
A Pandemia do Covid-19 e o Descortinamento das Vulnerabilidades da População LGBTQI+ Brasileira ${ }^{1}$
}

\author{
The Covid-19 Pandemic and the Exposure of the LGBTQI + Brazilian \\ Population Vulnerabilities
}

\author{
MARCELO HENRIQUE GONÇALVES DE MIRANDA \\ Professor Dr. do Núcleo de Formação Docente do Campus do Agreste/UFPE. \\ marcelo.gmiranda@ufpe.br \\ FERNANDA DO NASCIMENTO GRANGEÃO \\ Mestranda no Programa de Pós-Graduação em Direitos Humanos (PPGDH/UFPE). \\ fernandagrangeaoadv@gmail.com
}

FRANCISCO FERREIRA PIRES DE ALBUQUERQUE MONTENEGRO Mestrando no Programa de Pós-Graduação em Direitos Humanos (PPGDH/UFPE). chicomontenegro@gmail.com

\begin{abstract}
RESUMO
$\mathrm{O}$ artigo tem como objetivo mapear as facetas de vulnerabilidade que marcam o público LGBTQI+ brasileiro, potencializadas pela pandemia do SARS-CoV-2. A partir da Análise de Conteúdo se buscou categorizar as mensagens veiculadas nos dados coletados pelo Coletivo \#VoteLGBT (2020), nos dados produzidos pela OutRight Action International e nos dados da Associação Nacional de Travestis e Transexuais, a fim de identificar pontos nodais de vulnerabilidade notáveis à população LGBTQI+ brasileira e demonstrar um padrão de vulnerabilidade e de invisibilidade que ressoa e encontra semelhança em outros países. Perspectivas teóricas contemporâneas abordadas no estudo apontam que em um cenário permeado por tradições coloniais, exploratórias e discriminatórias há uma diferenciação entre vidas que merecem ser preservadas e vidas que são descartáveis. Por fim, foram trazidas iniciativas capitaneadas pela sociedade como boas práticas para evitar a perpetuação do silenciamento das vozes LGBTQI+.
\end{abstract}

Palavras-chave: Covid-19. LGBTQI+. Vulnerabilidades. Pandemia. SARS-CoV-2

\begin{abstract}
The article aims to map the vulnerability facets that mark Brazilian LGBTQI+ public, enhanced by the SARSCoV-2 pandemic. Based on Content Analysis, the messages conveyed in the data collected by the Collective \#VoteLGBT (2020), by OutRight Action International and by the National Association of Transvestites and Transsexuals were categorized in order to identify nodal points of vulnerability notable to LGBTQI + Brazilian population, demonstrating a pattern of vulnerability and invisibility that resonates and finds similarity in other countries. Contemporary theoretical perspectives addressed in the study point out that in a scenario permeated by colonial, exploratory and discriminatory traditions, there is a differentiation between lives that deserve to be preserved and lives that are disposable. Finally, initiatives led by society were brought up as good practices to avoid the perpetuation of the silencing of LGBTQI + voices.
\end{abstract}

Keywords: Covid-19. LGBTQI+. Vulnerabilities. Pandemic. SARS-CoV-2.

\footnotetext{
${ }^{1}$ Artigo submetido para avaliação em: 23/09/2020 e aprovado em: 30/10/2020.
} 
Rev. Interd. em Cult. e Soc. (RICS), São Luís, v. 6, n. 2, p. 102-119, jul./dez. 2020

ISSN eletrônico: $2447-6498$

\section{INTRODUÇÃO}

Em 11 de março de 2020 a Organização Mundial de Saúde (OMS) declarou que a COVID-19, doença causada pelo novo coronavírus (SARS-CoV-2), estaria caracterizada como uma pandemia. Àquela ocasião, o Diretor-Geral da OMS destacou que a enfermidade já teria atingido 114 países com o quantitativo de 118.000 casos e a marca de 4.291 mortes (WHO, 2020).

O vírus chega ao Brasil e o governo federal declara estado de calamidade pública a partir de 20 de março de 2020 (BRASIL, 2020). Amplificou-se no país uma nova realidade no intuito de conter o avanço da COVID-19, com o estímulo à população para a realização de isolamento social, a construção emergencial de hospitais de campanha e até o fechamento temporário de espaços públicos e de estabelecimentos comerciais.

Em que pesem as contradições havidas nas orientações emanadas do governo federal quanto às medidas necessárias ao combate à COVID-19 (MPF, 2020), em 22 de março de 2020, o Brasil atingiu seu percentual máximo de 62,2\% de isolamento social (MAPA, 2020).

Ocorre que, para além dos riscos físicos decorrentes de uma possível contaminação pelo SARS-CoV-2, a realidade socialmente imposta pelo combate ao vírus trouxe à tona, de forma patente, o extremo grau de vulnerabilidade a que estão sujeitas determinadas parcelas da sociedade, notadamente o público LGBTQI+, sobre o qual se concentrará o presente estudo.

Existe no imaginário social a ideia de que o surgimento de uma nova doença assumiria um alegado caráter democrático, por não distinguir seus sujeitos de contágio. Não à toa, a cartilha informativa elaborada pelo Ministério da Mulher, da Família e dos Direitos Humanos/Governo Federal, voltada ao público LGBTQI+, afirma, de início, que "lésbicas, gays, bissexuais, travestis e transgêneros estão expostos ao novo coronavírus da mesma forma que o resto da população" (BRASIL, 2020b, n. p).

No entanto, como será demonstrado neste artigo, a pandemia do SARS-CoV-2, enfraqueceu o manto de invisibilidade social e externou necessidades específicas da população LGBTQI+, afastando qualquer premissa democrática e universalizante de contágio.

Neste diapasão, a partir da comparação de dados constantes em pesquisas promovidas pelo Coletivo \#VoteLGBT ${ }^{2}$ (Diagnóstico LGBT+ na pandemia), pela organização OutRight

\footnotetext{
2 "Quem somos: \#VoteLGBT é um coletivo que desde 2014 busca aumentar a representatividade de LGBTs+ em todos os espaços, principalmente na política. Entendemos que a diversidade é um valor fundamental para a democracia. Por isso, também enxergamos a representatividade de forma interseccional às pautas de gênero e racial" (\#VoteLGBT, 2020, n. p.).
} 
Rev. Interd. em Cult. e Soc. (RICS), São Luís, v. 6, n. 2, p. 102-119, jul./dez. 2020

ISSN eletrônico: $2447-6498$

Action International (Vulnerability Amplified: The impact of the COVID-19 Pandemic on LGBTIQ People $)^{3}$, desenvolveu-se a interpretação dos dados por meio da Análise de Conteúdo (AC) (BARDIN, 1997; BAUER, 2010; GOMES, 2016) sobre os estudos conduzidos por tais entidades no intuito de serem estabelecidos os grupamentos semânticos, das fontes secundárias, derivados entre a experiência brasileira e a prática internacional no que se refere às repercussões advindas e potencializadas pela pandemia do novo coronavírus.

Assim, via Análise de Conteúdo se buscou categorizar as mensagens veiculadas nos dados coletados pelo Coletivo \#VoteLGBT (2020), nos dados produzidos pela OutRight Action International e nos dados da Associação Nacional de Travestis e Transexuais. A AC é "um conjunto de técnicas de análise de comunicações que utiliza procedimentos sistemáticos e objetivos de descrição do conteúdo das mensagens" (BARDIN, 1977, p. 38).

Nesse caminho, foram realizadas: a) uma leitura flutuante e cuidadosa das mensagens; b) a seleção dos trechos significativos das mensagens levando em consideração o objetivo da pesquisa; c) a eleição das unidades de registro relativas ao contexto social e aos referenciais teóricos-metodológicos; d) a formação das categorias temáticas por meio dos fragmentos das mensagens; e por último, e) as interpretações teóricas sobre as categorias temáticas (BARDIN, 1977; BAUER, 2010; GOMES, 2016).

Para além da metodologia de Análise de Conteúdo utilizada, foram trazidas as perspectivas teóricas de autores como BUTLER (2011; 2020); BENTO (2015; 2018); MBEMBE (2020); REIS (2020); SAFATLE (2020); SANTOS (2020); e SILVA (2020) como referencial analítico ao objetivo do estudo, consistente em mapear das facetas de vulnerabilidade que marcam o público LGBTQI+ brasileiro, potencializadas pela pandemia do SARS-CoV-2, à semelhança de experiências discriminatórias situadas em outros países.

Por fim, a partir das análises foram elencadas iniciativas capitaneadas pela sociedade como boas práticas para evitar a perpetuação do silenciamento das vozes LGBTQI+ nos seguintes eixos de atuação: solidariedade, trabalho e educação.

\section{UM GRITO DE VULNERABILIDADE A PLENOS PULMÕES}

\footnotetext{
3 “OutRight Action International luta pelos direitos humanos para a população LGBTIQ em todo lugar. OutRight trabalha em níveis internacionais, nacionais e regionais para pesquisar, documentar, defender e avançar nos direitos humanos para a população LGBTIQ em todo o mundo" (OutRight, 2020a, n. p.) (tradução nossa).
} 
Rev. Interd. em Cult. e Soc. (RICS), São Luís, v. 6, n. 2, p. 102-119, jul./dez. 2020

O estopim da pandemia da COVID-19, para além de externar preocupações acerca das repercussões sanitárias da disseminação do vírus, destacou a necessidade de realização de uma reflexão sobre a redistribuição desigual de vulnerabilidade (MBEMBE, 2020) nos diversos contextos sociais e culturais havidos em todo o globo. Diante do momento patogênico e catabólico enfrentado por diversas nações, o mundo apresentou sintomas de uma grande asfixia em que se retirou um direito básico, necessário e vital a qualquer pessoa: o direito universal à respiração (MBEMBE, 2020).

Seja pelo surgimento de um sentimento de pesar originado da possibilidade imediata e potencial de perda de entes queridos, seja em decorrência da imposição de realização do isolamento social ou, mesmo, da ausência de perspectiva de soluções mágicas ao cenário caótico que se apresentou, o novo coronavírus realçou um específico tipo de desamparo que aflige principalmente aqueles que (sobre)vivem em precárias situações: sua ampla vulnerabilidade social.

Todavia, não é o caso atribuir o afloramento de uma inédita crise de vulnerabilidade à explosão virulenta do SARS-CoV-2 nos últimos meses. O patógeno pode até assumir um caráter previamente desconhecido, mas a precariedade sobre a qual se entranhou já era uma realidade bastante sintomática da sociedade "globalizada". "A pandemia vem apenas agravar uma situação de crise a que a população mundial tem vindo a ser sujeita" (SANTOS, 2020, n. p.).

SANTOS (2020) metaforicamente afirma que os principais modos de dominação (capitalismo, colonialismo e patriarcado) são como três unicórnios, que transitam entre (i) um reino transcendental invisível - ocupado tanto pelo gigantesco divino, como pelo nanométrico vírus, (ii) um reino de causalidades, por onde tais seres míticos caminham promovendo suas articulações de forma sutil e, ao mesmo tempo, indomável, e (iii) um reino de consequências, onde revelam suas verdadeiras faces à humanidade, traduzindo paisagens de desigualdade social e de catástrofe ecológica. Para o autor, "todos os seres humanos são iguais (afirma o capitalismo); mas, como há diferenças naturais entre eles, a igualdade entre os inferiores não pode coincidir com a igualdade entre os superiores (afirmam o colonialismo e o patriarcado)" (SANTOS, 2020, n. p.).

Seguindo nas suas críticas quanto aos principais eixos de dominação, Santos ressalta os efeitos assimétricos que a quarentena provoca em distintos grupos, os quais ele chama de Sul. Para o autor, o Sul não seria propriamente um espaço geográfico, mas sim um espaço- 
tempo político, social e cultural. "É a metáfora do sofrimento humano injusto causado pela exploração capitalista, pela discriminação racial e pela discriminação sexual" (SANTOS, 2020, n. p.).

Inseridos em uma estrutura de poder voltada à aniquilação do outro (BUTLER, 2011; BENTO, 2018), os corpos da população LGBTQI+ (notadamente das pessoas trans), apresentam em suas peles cicatrizes de normas de regulação de sexualidade e de gênero. Cicatrizes de dominação promovidas não apenas no âmbito familiar, como também nas escolas, na política, na medicina, na justiça, no sistema prisional, na cultura e nas epistemologias (MIRANDA; OLIVEIRA, 2016; NOGUEIRA; MIRANDA, 2017; MIRANDA; LIMA, 2019), traduzindo-se em matrizes de ciscolonialidade ${ }^{4}$ (SILVA, 2020) e de heteronormatividade ${ }^{5}$.

Essa perspectiva de demarcação de espaços, de eliminação daqueles que não se subsumem às normas e de invisibilização de seus corpos, revela uma estrutura necrogovernamental (REIS, 2020) das instituições que, no curso de uma pandemia e do isolamento social, robustece vulnerabilidades pretéritas a que estes corpos estão sujeitos.

Aproximando a noção de necroestado à conjuntura brasileira em tempos pandêmicos, Vladimir Safatle se debruça sobre o conceito de "estado suicidário", apresentado por Paul Virilio, e propõe que "caminhamos em direção para um além da temática necropolítica do estado como gestor da morte e do desaparecimento" (SAFATLE, 2020). Safatle assinala, então, que o estouro da pandemia no Brasil foi a catástrofe perfeita para a promoção de um "flerte contínuo com a morte generalizada" (SAFATLE, 2020, n. p.).

É claro que tal estado se funda nessa mistura tão nossa de capitalismo e
escravidão, de publicidade de coworking, de rosto jovem de
desenvolvimento sustentável e indiferença assassina com a morte reduzida a
efeito colateral do bom funcionamento necessário da economia. [...] A
história do Brasil é o uso contínuo dessa lógica. A novidade é que agora ela
é aplicada a toda a população. Até bem pouco tempo, o país dividia seus
sujeitos entre "pessoas" e "coisas", ou seja, entre aqueles que seriam tratados
como pessoas, cuja morte provocaria luto, narrativa, comoção e aqueles que
seriam tratados como coisas, cuja morte é apenas um número, uma fatalidade
da qual não há razão alguma para chorar. Agora, chegamos à consagração

\footnotetext{
${ }^{4}$ Mariah Rafaela Silva (2020) explica a ciscolonialidade como "um domínio no campo do corpo, do gênero, da sexualidade, construindo efetivamente o paradigma de 'verdade' das inteligibilidades sociais" que tem como referência um corpo "natural", "branco" e heterossexual. Em um viés interseccional, Carla Akotirene (2019) também aponta para a existência de uma matriz colonial moderna e afirma que a colisão de eixos de subordinação estrutural, tais como o racismo, o capitalismo e o cisheteropatriarcado, permite a visualização do gênero, da raça e da classe como aparatos coloniais em mútuo e simultâneo entrecruzamento.

${ }_{5}^{5}$ A partir da descriminalização e da desconstrução da homossexualidade como doença, a heteronormatividade pode ser definida como um "marco de controle e normalização da vida de gays e lésbicas, não mais para que se 'tornem heterossexuais', mas com a finalidade de que vivam como eles" (MISKOLCI, 2009, p. 157).
} 
Rev. Interd. em Cult. e Soc. (RICS), São Luís, v. 6, n. 2, p. 102-119, jul./dez. 2020

ISSN eletrônico: $2447-6498$

final desta lógica. A população é apenas o suprimento descartável para que o processo de acumulação e concentração não pare sob hipótese alguma (SAFATLE, 2020, n. p.).

Talvez as facetas mais sintomáticas desse flerte macabro havido no Brasil durante a pandemia sejam a explosão de notícias falsas, o retorno a um discurso anticientífico, a naturalização dos números referentes às mortes provocadas pelo SARS-CoV-2 e o ataque às manifestações públicas de luto.

Afirmações como: “todos nós iremos morrer um dia", “eu não sou coveiro, tá?” e "e daí? Quer que eu faça o quê?”, foram proferidas pelo Presidente da República em dias distintos, nessa ordem, quando indagado acerca da evolução dos números de mortes decorrentes da COVID-19 no Brasil (TAJRA, 2020).

Em um panorama de ultravelocidade de dados e de massificação de informações, o cenário pandêmico apontou para a eclosão de um discurso anticientífico cujo efeito silenciador (à semelhança do discurso de ódio) voltou-se aos grupos de maior vulnerabilidade social, no intuito de calá-los e de impedir a sua participação no debate público (MONTENEGRO, 2019; FISS, 2005). Lamentos, choros e gritos são intolerados, o que importaria ao Estado brasileiro é um único sobrevivente: a economia.

Nesse contexto, manifestações públicas de luto foram invadidas e depredadas por apoiadores do governo federal, no claro intuito de silenciar as vozes de pessoas que, além de chorarem as perdas de seus entes queridos, clamavam por uma melhor assistência do Estado às famílias em situação de vulnerabilidade durante a crise da COVID-196 .

Butler nos adverte que nossa sociedade frequentemente é particionada entre aquelas vidas que merecem proteção e aquelas tidas como prescindíveis. "Dependendo do gênero, da raça e da posição econômica que ostentamos na sociedade, podemos sentir se somos mais ou menos choráveis aos olhos dos demais" (BUTLER, 2020, n. p.).

Indaga-se, então, se não seriam aquelas vidas dignas de serem lamentadas? Seriam sequer vidas dignas de serem vividas? Quais os perfis sociais, raciais, geracionais, de gênero e de sexualidade que marcaram a vida daquelas pessoas? Tais questionamentos são indispensáveis, sobretudo tendo em conta que o Brasil, em 22 de setembro de 2020, dia em que encerrada a presente pesquisa, ostenta o terceiro lugar mundial em número de casos -

\footnotetext{
${ }^{6}$ Nesse sentido reportagens veiculadas pelo portal G1 (Homens invadem ato no Rio e um deles derruba cruzes que lembram mortos pela Covid) e Leia Já (Bolsonarista vandaliza homenagem à vítimas da Covid-19), relatam o cenário de intolerância e de tentativa de silenciamento de manifestações públicas realizadas nas cidades do Rio de Janeiro/RJ e de Recife/PE (ALVES, 2020; BOLSONARISTA, 2020).
} 
Rev. Interd. em Cult. e Soc. (RICS), São Luís, v. 6, n. 2, p. 102-119, jul./dez. 2020

ISSN eletrônico: $2447-6498$

4.566.123 - e de mortes - 137.445 - por COVID-19 (CORONAVIRUS, 2020), demonstrando que paira no país "uma atmosfera, uma toxicidade que invade o ar" (BUTLER, 2020, n. p.) e, tal como o SARS-CoV-2, furta a respiração de suas vítimas e abafa seus gritos de vulnerabilidade.

\section{A CRISE, AS PESQUISAS E A IDENTIFICAÇÃO DOS PONTOS NODAIS DE VULNERABILIDADE}

Pesquisas anteriores à pandemia já demonstravam que o contexto social vivenciado no Brasil era preocupante. Nesse sentido, dados coletados pelo IBGE apontaram o aumento no índice de desemprego, atualizado no primeiro semestre do ano de 2020 para a cifra de 12,9 milhões, o que corresponde a uma taxa nacional de 11,9\% de desemprego (IBGE, 2020).

Pode-se afirmar, portanto, que já havia uma crise econômica e política instalada no país quando do início da pandemia do novo coronavírus que, contudo, foi amplificada quando da disseminação do SARS-CoV-2 em todo o território nacional e expôs, ainda mais, a vulnerabilidade sistêmica a que está sujeita a população LGBTQI+.

No intuito de melhor compreender as repercussões em face da população LGBTQI+ brasileira, potencializadas no período de isolamento social decorrente do COVID-19, o coletivo \#VoteLGBT realizou uma pesquisa quantitativa com espectro nacional de abordagem, posteriormente submetida à análise qualitativa do grupo Box1824 (\#VoteLGBT, 2020).

Referido levantamento quali-quantitativo contabilizou mais de dez mil respostas, distribuídas em todas as regiões geográficas do país, com maior percentual de participação nos estados do Sudeste $(59,95 \%)$ e do Nordeste (16,85\%), seguidos do Sul (13,52\%), CentroOeste $(6,72 \%)$ e Norte $(2,96 \%)$ (\#VoteLGBT, 2020).

No aspecto raça, a maioria dos participantes foi composta por brancos $(61,41 \%)$, seguidos por pardos $(24,81 \%)$, pretos $(11,67 \%)$, amarelos $(1,66 \%)$ e indígenas $(0,45 \%)$. No recorte de sexualidade, os números foram de 45,86\% (gays), 29,72\% (bissexuais/pansexuais), 21,42\% (lésbicas), 1,70\% (não sabida) e 1,30\% (heterossexuais, em menor número por opção metodológica dos responsáveis pela pesquisa). Por fim, no eixo de identidade de gênero, os registros de participação foram de 50,77\% (homens cis), 40,15\% (mulheres cis), 5,49\% (nãobinários $^{7}$ ), 1,93\% (homens trans), 1,28\% (mulheres trans) e 0,37\% (travestis) (\#VoteLGBT, 2020).

\footnotetext{
${ }^{7}$ Em artigo intitulado "Travesti", "mulher transexual", "homens trans" e "não binário": interseccionalidades de
} 
Rev. Interd. em Cult. e Soc. (RICS), São Luís, v. 6, n. 2, p. 102-119, jul./dez. 2020

ISSN eletrônico: $2447-6498$

Como ponto de partida para análise dos resultados obtidos, o coletivo \#VoteLGBT destacou que o caráter virtual da pesquisa, que foi realizada integralmente pela internet em razão das restrições de deslocamento impostas pela pandemia, já espelhou a dificuldade de inserção social quanto aos eixos sub-representados na pesquisa: região norte, indígenas, travestis, homens trans e mulheres trans.

A conclusão que nos parece mais relevante é que, mesmo sem conseguir atingir toda a diversidade da população LGBT+, o resultado da crise do novo coronavírus sobre esta população já se mostra muito negativo. Lamentavelmente, podemos imaginar que para aqueles ainda não bem representados nesta amostra, a situação pode ser ainda pior (\#VoteLGBT, 2020, p. 7).

No que se refere aos demais resultados, a pesquisa apontou que os três maiores impactos da pandemia do SARS-CoV-2 na população LGBT foram a piora na saúde mental $(42,72 \%)$, sucedida pelo afastamento da rede de apoio (16,58\% - novas regras de convívio social; $11,74 \%$ - solidão e $10,91 \%$ - convívio familiar) e pela falta de fonte de renda $(10,62 \%$ - falta de dinheiro e 7,0\% - falta de trabalho) (\#VoteLGBT, 2020).

Os relatos observados pela pesquisa capitaneada pelo \#VoteLGBT alinham-se aos resultados obtidos pela organização OutRight Action International, em estudo qualitativo realizado em âmbito global, estruturado na realização de 59 entrevistas com representantes de 38 países $^{8}$ entre o fim de março e o início de abril de 2020 (OUTRIGHT, 2020b).

Das entrevistas conduzidas pela OutRight Action International, exsurgiram sete eixos de destaque à vulnerabilidade sofrida pelo público LGBTQI+: i) devastação dos meios de subsistência e crescente insegurança alimentar; ii) interrupções no acesso a cuidados de saúde e relutância em procurar atendimento; iii) risco elevado de violência familiar ou doméstica; iv) isolamento social e aumento da ansiedade; v) medo de violência social, estigma, discriminação e "bode expiatório"; vi) abuso do poder estatal e vii) preocupações sobre sobrevivência organizacional, suporte comunitário e unidade da comunidade LGBTQI+ (OUTRIGHT, 2020b).

classe e geração na produção de identidades políticas, Mario Carvalho (2018) relata suas observações do I Encontro Nacional de Homens Trans, realizado em 2015, e traz a ideia de não binário como uma importação da expressão adotada em países de língua inglesa (non binary person), que poderia ser definida uma categoria identitária que tentaria dar concretude à multiplicidade de gêneros situados entre os polos tradicionalmente ocupados pelas noções de homem e de mulher.

8 Conforme registros expostos pela OutRight Action International, participaram do estudo entrevistados provenientes do Sudeste, Leste e Sul Asiático, Oriente Médio e Norte Africano, Norte, Leste e Oeste Europeu, África Subsaariana, América Latina, Caribe, Oceania e América do Norte (OUTRIGHT, 2020b, p. 12). 
Rev. Interd. em Cult. e Soc. (RICS), São Luís, v. 6, n. 2, p. 102-119, jul./dez. 2020

ISSN eletrônico: $2447-6498$

O cenário que se observa, então, é o de que os resultados obtidos pelas duas pesquisas convergem na identificação dos pontos nodais da vulnerabilidade do público LGBTQI+: trabalho/renda, saúde física/mental (inclusive sob a perspectiva da violência) e solidariedade (redes de apoio e pertencimento comunitário).

É curioso ressaltar que algumas situações narradas pelas pessoas entrevistadas pela OutRight Action International, apesar de aparentarem um caráter excepcional, inequivocamente se repetem na realidade brasileira e demonstram um retrato de como se operam as opressões contra a população LGBTQI+ em diversas regiões do mundo. Tal fato nos indica uma estrutura de inteligibilidade essencialista que (re)produz e aumenta a lgbtfobia (BUTLER, 2003; BORRILLO, 2010; SILVA; MIRANDA; SANTOS, 2020) em um contexto da pandemia do SARS-CoV-2.

De início, cita-se o receio de ser o "bode expiatório" para a atribuição de responsabilidade para as crises mundiais, já que o estabelecimento de uma relação de causaconsequência entre a população LGBTQI+ e os mais diversos problemas que acometem a humanidade não é uma conduta rara entre líderes conservadores.

A escolha de um "bode expiatório" não foi diferente no curso da pandemia, pois, há registros de culpabilização do público LGBTQI+ pela disseminação do vírus SARS-CoV-2 em países como “Gana, Guiana, Quênia, Libéria, Rússia, Uganda, Ucrânia, Estados Unidos e Zimbábue" (OUTRIGHT, 2020b, p. 52).

Nesse mesmo caminho pela imposição da indicação de culpa fantasiosa, destaca-se que, aqui no Brasil, em 2014, um líder religioso buscou atribuir a culpa da estiagem na cidade de São Paulo à realização da parada gay, chegando, inclusive, a afirmar que a seca local seria o "cálice da ira de Deus derramando-se" (PASTOR, 2014).

Outra situação a ser sublinhada foi a dificuldade de acesso pelo público LGBTQI+ aos benefícios governamentais relacionados à crise potencializada pela COVID-19. Relatos provenientes de mulheres lésbicas filipinas descreveram a impossibilidade de serem contempladas com ajuda alimentar fornecida pelo governo em razão de suas famílias homoafetivas não se enquadrarem no perfil familiar legalmente previsto (OUTRIGHT, 2020b). Concomitantemente, no Brasil, pessoas transgêneros noticiaram dificuldades para percepção do auxílio emergencial pago pelo Governo Federal devido às inconsistências sistêmicas em relação ao uso do nome social (OLIVA, 2020).

Sobre o domínio do que chama de "cis-ficção", constituídas a partir de critérios de extermínio, segregação e separação, Mariah Rafaela Silva (2020) enuncia os corpos trans 
Rev. Interd. em Cult. e Soc. (RICS), São Luís, v. 6, n. 2, p. 102-119, jul./dez. 2020

ISSN eletrônico: $2447-6498$

racializados como commodities,

O mesmo corpo que, desde sempre isolado, não pode usufruir do isolamento promovido pelas políticas de quarentena, seja porque a família tradicional o rejeita, seja porque as dinâmicas estruturais de pobreza não permitem. Esse mesmo corpo-subjetividade, abjeto durante o dia e clandestino durante as noites, não pode acessar o auxílio emergencial por não ter documento ou muitas vezes ser menor de idade (SILVA, 2020, n. p.).

Seguindo um recorte identitário, a ANTRA, em pesquisa divulgada em 2018, traz a informação de que $90 \%$ da população trans brasileira utiliza a prostituição como fonte de renda (BENEVIDES, 2018). Contudo, com o surgimento da pandemia e diante da necessidade de isolamento social, tornou-se desaconselhável a essa parcela da população que realizasse a única atividade que lhe garante renda para sua subsistência, dados os elevados riscos de contágio e insegurança de trabalhos externos.

Como último destaque, chama-se a atenção para o fato de que a representação maximizada de mulheres trans enquanto profissionais do sexo e os riscos advindos de suas atividades (ou inatividades) no curso da pandemia não seria uma realidade excepcional experienciada apenas no Brasil.

Relatos provenientes da Bélgica, África do Sul e Guiana, consolidados nas entrevistas conduzidas pela OutRight (2020b) apontam uma específica preocupação em face da vulnerabilidade econômica vivenciada por tal parcela da comunidade LTBQI+:

Particularmente mulheres trans, são desproporcionalmente representadas em trabalhos sexuais devido à discriminação existente em outros setores como emprego e educação (OUTRIGHT, 2020b, p. 31) (Tradução nossa).

Neste particular, é relevante salientar que, no objetivo de sintetizar os diversos marcadores interseccionais da população brasileira, o coletivo \#VoteLGBT (2020) desenvolveu em seu estudo um "índice de vulnerabilidade LGBT+ à Covid-19”, que indicou as pessoas trans (no segmento gênero) e o público preto/pardo/indígena, na perspectiva racial, como os segmentos de mais grave vulnerabilidade no país. Trouxe a pesquisa:

Se o fator que mais diferencia o peso do impacto emocional e social é a idade, quando se trata do financeiro, sem dúvida alguma a realidade é muito mais devastadora para a população trans. Assim como o resto da população, a idade e a raça também impactam diretamente na empregabilidade. $\mathrm{O}$ acesso ao mercado de trabalho, especialmente em salários e cargos superiores, é tangivelmente mais difícil para pretos, pardos e indígenas, assim como para pessoas de idades mais altas. Mas, quando se trata da população trans, que sofre muito mais com a expulsão do ambiente familiar 
Rev. Interd. em Cult. e Soc. (RICS), São Luís, v. 6, n. 2, p. 102-119, jul./dez. 2020

ISSN eletrônico: $2447-6498$

e educacional, o acesso, mesmo a cargos de base, é praticamente inviabilizado (\#VOTELGBT, 2020, p. 20).

Mais uma vez, percebe-se que os resultados trazidos pelas recentes pesquisas desenvolvidas pelo coletivo \#VoteLGBT e pela organização OutRight Action International se alinham aos mais alarmantes números trazidos pela ANTRA em relação à população transgênera. Em recente estudo apresentado pela ANTRA, identificou-se que o Brasil permanece no ranking dos países com os maiores índices de assassinatos de pessoas trans, inclusive com um aumento percentual $13 \%$ de mortes em comparação ao mesmo período de 2019 (março-abril), quando não havia isolamento social. Se levado em consideração todo o período entre janeiro e abril de 2020, o aumento de assassinatos verificado é de $48 \%$ em relação a 2019 (BENEVIDES, 2020c).

A conclusão a que se chega, a partir da aproximação dos dados provenientes de todas as pesquisas acima mencionadas, é a existência de um padrão de vulnerabilidade e de invisibilidade em desfavor da população LGBTQI+. Vale ressaltar que tal situação não se restringe ao Brasil, ela assume contornos globais.

Claro que o protagonismo brasileiro de um governo recém eleito sob uma pauta conservadora e anti-LGBTQI+ (LOPES, 2018) amplifica as nefastas repercussões, sobretudo em desfavor de pessoas trans e travestis. Contudo, conforme demonstram os resultados referenciados nas pesquisas realizadas pelo \#VoteLGBT e pela OutRight Action International, aliados às informações disponibilizadas pela ANTRA, a pandemia do novo coronavírus descortinou o véu de uma "LGBTTTTfobia cordial" (BENTO, 2015) que historicamente cobre o público LGBTQI+ e revelou a pré existência de questões sociais basilares não atendidas.

\section{BOAS PRÁTICAS - SOLIDARIEDADE, TRABALHO E EDUCAÇÃO}

O caráter asfixiante do quadro em que se encontra a população LGBTQI+ brasileira é inegável. As pesquisas supramencionadas espelham o grau de extrema vulnerabilidade a que está sujeito tal público e alertam para o risco da perpetuação de sua invisibilização.

Contudo, se a crise está posta desde muito tempo e se não há interesse em formular uma política de governo voltada à sua solução, é importante reconhecer e valorar adequadamente iniciativas capitaneadas pela sociedade que, em um legítimo sentimento de 
Rev. Interd. em Cult. e Soc. (RICS), São Luís, v. 6, n. 2, p. 102-119, jul./dez. 2020

ISSN eletrônico: $2447-6498$

alteridade, procuraram atenuar repercussões negativas contra a população LGBTQI+, potencializadas pela pandemia.

Durante o período de intenso isolamento social, em todo o país e no mundo, foram realizadas várias práticas de solidariedade e comprometimento com a população LGBTQI+, com o objetivo de cuidar e amparar aqueles que foram excluídos de suas famílias por atos de rejeição e de violência, ou seja, por lgbtfobia.

A preocupação com a saúde mental através de atendimentos por videoconferência com psicólogos e terapeutas, a preocupação com a saúde do corpo para os que interromperam os tratamentos de hormonização e tratamentos contra o vírus do HIV e principalmente a sobrevivência daqueles que necessitam de um lar deram espaço para que várias redes mobilizassem campanhas solidárias de arrecadação no Brasil e no mundo.

Como exemplo dessas campanhas, a publicação da Revista Híbrida que, em parceria com a ANTRA e ABGLT, lançou uma lista das principais ONG's, grupos e instituições em diversos estados da federação (BENEVIDES, 2020b), disponibilizando telefones para contato e redes sociais, com os dados necessários para contribuição e a confirmação do recebimento.

Afora as medidas adotadas por entidades representativas como a ANTRA e a ABGLT, elenca-se, neste estudo, outras ações em três eixos de atuação: solidariedade, trabalho e educação.

No plano solidariedade, destaca-se a atuação do Núcleo de Gestão do Porto Digital (Projeto Porto+), em Recife, que, além de arrecadar fundos para pessoas trans em situação de vulnerabilidade, promoveu amplos debate virtuais nas suas plataformas de redes sociais com a campanha Mês urgenT (PORTO DIGITAL, 2020).

Em relação ao segmento trabalho, o portal Transempregos lançou o projeto TRANSformAção, que pretende capacitar o público trans para a conquista de vagas de trabalho mediante a disponibilização gratuita de treinamentos de habilidades digitais, de conhecimentos jurídicos e de análises de mercado (TRANSEMPREGOS, 2020).

Por fim, na área de educação, identifica-se na Universidade Federal de Pernambuco um projeto de atenção à população LGBT, no curso da pandemia, mediante a concessão de bolsas de estudo (PROJETO, 2020). No âmbito internacional, também surgem práticas que merecem destaque, como a adoção obrigatória de disciplina de história LGBTQ+ nas escolas públicas da Escócia e de Seattle/EUA (UNIVERSIA, 2020a; 2020b).

Portanto, em que pese o nítido desinteresse estatal em resolver (ou mesmo atenuar) as desigualdades sociais que marcam a população LGBTQI+ brasileira, o que é de se esperar 
Rev. Interd. em Cult. e Soc. (RICS), São Luís, v. 6, n. 2, p. 102-119, jul./dez. 2020

ISSN eletrônico: $2447-6498$

diante da regência de uma inegável estrutura necrogovernamental (REIS, 2020), percebe-se, com esperança, o recrudescimento na sociedade de um sentimento de reinvenção do "normal", o despontamento de uma alteridade voltada não apenas a suprir as necessidades imediatas do outro ocultado, mas, sobretudo, destinada à reconstrução de suas trajetórias futuras garantindo-lhe reconhecimento, visibilidade e protagonismo.

\section{CONSIDERAÇÕES FINAIS}

Se quando da declaração da pandemia pela Organização Mundial de Saúde, em 11 de março de 2020, os números referentes à COVID-19 causavam apreensão, na data de encerramento deste trabalho, em setembro de 2020, a situação ultrapassa o caos.

Países que relaxaram medidas de contingenciamento social após suposto controle de casos (a exemplo de Espanha e França), agora se veem desafiados à decretação de novas quarentenas obrigatórias ante o receio de uma segunda onda de contaminação (SEGUNDA, 2020). Já o Brasil, cuja primeira onda de contágio sequer pode ser encarada como finalizada, excedeu o quantitativo de cento e trinta mil mortes e de mais de quatro milhões de infectados, situando-se em números de casos atrás apenas dos Estados Unidos e da Índia (CORONAVIRUS, 2020).

Há de se ressaltar que no interior de tais números não é possível obter informações acerca de qual o percentual do público LGBTQI+ atingido pela COVID-19, já que a diversidade sexual e de gênero não integra a maioria dos critérios de indexação das estatísticas brasileiras ou internacionais.

Contudo, os resultados observados nas pesquisas abordadas nesse trabalho não permitem negar as severas intempéries que a pandemia do COVID-19 vem potencializando às já existentes na população LGBTQI+. Assim, as pesquisas reunidas neste artigo demonstram que existe um padrão de vulnerabilidade e de invisibilidade brasileiro que ressoa e encontra semelhança em outros países.

Não obstante, apesar do cenário brasileiro desfavorável aos direitos LGBTQI+ haver se intensificado no curso da pandemia, diante da atuação de um Estado "suicidário" comprometido com sua pauta necrófila, diversas ações sociais despontaram para dar vez e voz à comunidade LGBTQI+.

Claro que os possíveis impactos das medidas relacionadas neste último ponto são ínfimos diante da magnitude das chagas sociais a que sujeito o público LGBTQI+. Todavia, 
Rev. Interd. em Cult. e Soc. (RICS), São Luís, v. 6, n. 2, p. 102-119, jul./dez. 2020

ISSN eletrônico: $2447-6498$

outras práticas devem ser destacadas para evitar a perpetuação do silenciamento das vozes e extermínio da população LGBTQI+ que gritam por reconhecimento e por redistribuição.

\section{REFERÊNCIAS}

AKOTIRENE, Carla. Interseccionalidade. Pólen Produção Editorial LTDA, 2019.

ALVES, Raoni. Homens invadem ato no Rio e um deles derruba cruzes que lembram mortos pela Covid. G1 - Rio de Janeiro, 2020. Disponível em < https://g1.globo.com/rj/rio-dejaneiro/noticia/2020/06/11/grupo-ataca-manifestacao-que-lembra-mortos-pela-covid-19-norio.ghtml> Acessado em: 22/07/2020.

BARDIN, Lawrence. Análise de Conteúdo. Lisboa, Edições 70, 1997.

BAUER, Martin. W. Análise de Conteúdo clássica: uma revisão. In BAUER, M. W.; GASKELL, G. (Orgs.). Pesquisa Qualitativa com Texto, Som e Imagem: um manual prático. Petrópolis, Vozes, 2010.

BENEVIDES, Bruna. Mapa dos assassinatos de Travestis e Transexuais no Brasil em 2017. ANTRA, 2018. Disponível em: <https://antrabrasil.files.wordpress.com/ 2018/02/relatc3b3rio-mapa-dos-assassinatos-2017-antra.pdf>. Acessado em: 22/07/2020.

Dicas para travestis e mulheres trans profissionais do sexo em tempos

de Covid-19. ANTRA, 2020a. Disponível em: $<$ https://antrabrasil.files. wordpress.com/2020/04/dica-profissionais-do-sexo-covid19-antra.pdf > Acessado em: 20/07/2020.

Instituições LGBTQI+ lançam campanha coletiva para o

CORONAVÍRUS; saiba como doar. Híbrida, 2020b. Disponível em:

$<$ https://revistahibrida.com.br/2020/04/15/instituicoes-lgbtqi-lancam-campanha-coletiva-parao-coronavirus-saiba-como-doar/> Acesso em 21/07/2020.

BENEVIDES, Bruna; NOGUEIRA, Sayonara. Boletim n. 02/2020. ANTRA, 2020c.

Disponível em: <https://antrabrasil.files.wordpress.com/2020/05/boletim- 2-2020assassinatos-antra.pdf $>$ Acessado em: 22/07/2020.

BENTO, Berenice. "Pinkwashing à brasileira": do racismo cordial à LGBTTTfobia cordial. Cult, 2015. Disponível em: < https://revistacult.uol.com.br/home/pinkwashing-brasileira-doracismo-cordial-lgbtttfobia-cordial> Acessado em: 22/07/2020.

. Necrobiopoder: Quem pode habitar o Estado-nação? Cadernos Pagu,

Campinas, n. 53, e185305, 2018. Disponível em

<http://www.scielo.br/scielo.php?script=sci_arttext\&pid=S0104-

83332018000200405\&lng=pt\&nrm=iso>. Acessado em: 07/07/2020. Epub 11-Jun-2018.

http://dx.doi.org/10.1590/18094449201800530005. 
Rev. Interd. em Cult. e Soc. (RICS), São Luís, v. 6, n. 2, p. 102-119, jul./dez. 2020

ISSN eletrônico: $2447-6498$

BOLSONARISTA vandaliza homenagem a vítimas da Covid-19. Leia já, 2020. Disponível em: <https://www.leiaja.com/noticias/2020/07/04/bolsonarista- vandaliza-homenagem vitimas-da-covid-19>. Acessado em: 22/07/2020.

BORRILLO, Daniel. História e crítica de um preconceito. Belo Horizonte, Autêntica, 2010. BRASIL. Decreto Legislativo n. 06/2020, 2020a. Disponível em $<$ http://www.planalto.gov.br/ccivil_03/portaria/DLG62020.htm\#: :text=DECRETO\%20LEGISLATIVO\%20N\%C2\%BA\%206\%2C\%20DE, $18 \% 2$ 0de\%20mar\%C3\%A7o\%20de\%202020> Acessado em: 22/07/2020.

. Já sabe o que fazer para se proteger do novo coronavírus? Ministério da Mulher, da Família e dos Direitos Humanos, 2020b. Disponível em: <https://www.gov.br/mdh/ptbr/assuntos/noticias/2020-2/abril/Corona_banner_LGBT.pdf $>$ Acessado em: 22/07/2020.

BUTLER, Judith. Problemas de gêneros: feminismo e subversão da identidade. Rio de Janeiro Civilização Brasileira, 2003.

1, p. 13-33, 2011.

. Vida precária. In Contemporânea-Revista de Sociologia da UFSCar. n.

. "De quem são as vidas consideradas choráveis em nosso mundo público?". EI País, 2020. Disponível em: https://brasil.elpais.com/ babelia/2020-07-10/judith-butler-dequem-sao-as-vidas-consideradas-choraveis-em-nosso-mundo-publico.html> Acessado em: 22/07/2020.

CARVALHO, Mario. "Travesti", "mulher transexual", "homem trans" e "não binário": interseccionalidades de classe e geração na produção de identidades políticas. Cad. Pagu, Campinas , n. 52, e185211, 2018. Disponível em:

$<$ http://www.scielo.br/scielo.php?script=sci_arttext\&pid=S0104-

83332018000100501\&lng=en\&nrm=iso>. Acessado em: 23/09/2020.

CORONAVIRUS (Covid 19) Worldwide. Google News, 2020. Disponível em: <https://news.google.com/covid19/map?hl=en-US\&gl=US\&ceid=US\%3Aen>Acessado em: 22/09/2020.

COVID-19: pesquisador esclarece quais cuidados devem ser tomados com os animais domésticos. Fiocruz, 2020. Disponível em: $\langle$ https://portal.fiocruz.br/noticia/covid-19pesquisador-esclarece-quais-cuidados-devem-ser-tomados-com-os-animais-domesticos> Acessado em: 22/07/2020.

FISS, Owen M. A ironia da liberdade de expressão - Estado, regulação e diversidade na esfera pública. Tradução de Gustavo Binenbojm e Caio Mário da Silva Pereira Neto. Rio de Janeiro: Renovar, 2005.

GOMES, Romeu. Análise e Interpretação de dados de Pesquisa Qualitativa. In MINAYO, M. C. de S. (Org.). Pesquisa Social: teoria, método e criatividade. Petrópolis, Vozes, 2016.

IBGE. Desemprego. IBGE, 2020. Disponível em:<https://www.ibge.gov.br/explica/desemprego.php> Acessado em: 20/07/2020. 
Rev. Interd. em Cult. e Soc. (RICS), São Luís, v. 6, n. 2, p. 102-119, jul./dez. 2020

ISSN eletrônico: $2447-6498$

LOPES, Marina. More than fear: Brazil's LGBT community dreads looming Bolsonaro presidency. Washington Post, 2018. Disponível em: <https://link-

gale.ez16.periodicos.capes.gov.br/apps/doc/A559865204/AONE?u=capes\&sid=AONE\&xid= 09fbaa28>. Acessado em: 20/07/2020.

MAPA brasileiro da COVID-19. InLoco, 2020. Disponível em:

<https://mapabrasileirodacovid.inloco.com.br/pt/> Acessado em: 22/07/2020.

MBEMBE, Achille. O direito universal à respiração. N-1 edições, 2020. Disponível em: <https://n-1edicoes.org/020> Acessado em: 22/07/2020.

MIRANDA, Marcelo H. Gonçalves; LIMA, Larissa S. G. A. A prática pedagógica dos direitos humanos: marcadores sociais da diferença e o combate ao bullying. In Revista Momento -Diálogos em Educação, v. 28, n. 1, p. 328-348, 2019.

MIRANDA, Marcelo H. Gonçalves; OLIVEIRA, Ana C. A. Os Limites das categorias Heteronormativas no Cotidiano Escolar e a Pedagogia Queer: o caso do uso do banheiro. In Educação e Cultura Contemporânea, v. 13, p. 350-373, 2016.

MISKOLCI, Richard. A Teoria Queer e a Sociologia: o desafio de uma analítica da normalização. In Sociologias, n. 21. v. 337, 2009.

MONTENEGRO, Francisco F. P. de Albuquerque. Liberdade de expressão e de comunicação na mídia brasileira: uma análise do direito de resposta coletivo. In Temas do Ministério Público: acordos no sistema de justiça e liberdade de expressão, p. 431-458, Brasília: ANPR, 2019.

MPF processa governo por contradições de medidas contra coronavírus. Veja, 2020.

Disponível em: <https://veja.abril.com.br/blog/radar/mpf-processa-governo-porcontradicoes-de-medidas-contra-coronavirus $>$ Acesso em: 22/07/2020.

NOGUEIRA, Christina G. M.; MIRANDA, Marcelo H. Gonçalves. A (re)produção das masculinidades hegemônicas: homens, famílias populares e violações dos direitos humanos. In Revista Interritorios, v. 3, p. 120-140, 2017.

OLIVA, Gabriela. Auxílio emergencial: transgêneros relatam problemas para receber suporte de R\$ 600 do governo usando o nome social. O Globo, 2020. Disponível $\mathrm{em}:<$ https://oglobo.globo.com/sociedade/auxilio-emergencial-transgeneros-relatamproblemas-para-receber-suporte-de-600-do-governo-usando-nome-social-24439275> Acessado em: 22/07/2020.

OUTRIGHT, Action International. About us, 2020a. Disponível em <https://outrightinternational.org/about-us > Acessado em: 22/07/2020.

Action International. VULNERABILITY AMPLIFIED: The Impact of the COVID-19 Pandemic on LGBTIQ People, 2020b. Disponível em $<$ https://outrightinternational.org/sites/default/files/COVIDsReportDesign_FINAL_LR_0.pdf $\geq$ Acessado em: 22/07/2020. 
Rev. Interd. em Cult. e Soc. (RICS), São Luís, v. 6, n. 2, p. 102-119, jul./dez. 2020

ISSN eletrônico: $2447-6498$

PASTOR culpa Parada Gay por seca em São Paulo. BandRio, 2014. Disponível em: <https://bandrio.band.uol.com.br/noticias/100000718628/pastorculpaparadagayporsecaemsao paulo.html.html.html.html> Acessado em: 22/07/2020.

PORTO DIGITAL. Porto Digital lança campanha para ajudar pessoas trans e travestis durante a pandemia. Porto Digital, 2020. Disponível em: <https://portodigital.org/119/37997-portodigital-lanca-campanha-para-ajudar-pessoas-trans-e-travestis-durante-a-pandemia $>$ Acessado em: 22/07/2020.

PRESTES, Maria Luci de Mesquita. A pesquisa e a construção do conhecimento científico: do planejamento aos textos, da escola à academia. 2. ed. São Paulo: Rêspel, 2003.

PROJETO de atenção à população LGBT durante a pandemia seleciona bolsistas. UFPE | Covid-19, 2020. Disponível em: <https://www.ufpe.br/covid-19/extensao-e- cultura//asset_publisher/vjchTXZZBAJ2/content/projeto-de-atencao-a-populacao-lgbt-durante-apandemia-seleciona-bolsistas/40659>Acessado em: 22/07/2020.

REIS, Diego. Pensamentos pós-coroniais. N-1 edições, 2020. Disponível em: 〈https://n1edicoes.org/120> Acessado em: 22/07/2020.

SAFATLE, Vladimir. Bem vindo ao estado suicidário. N-1 edições, 2020. Disponível em: <https://n-1edicoes.org/004>. Acessado em: 22/07/2020.

SANTOS, Boaventura de Sousa. A cruel pedagogia do vírus. Ebook. Coimbra: Almedina, 2020.

SEGUNDA onda de coronavírus: países da Europa levam 'advertência' da OMS e planejam novas quarentenas. BBC, 2020. Disponível em:

<https://www.bbc.com/portuguese/internacional-54202548> Acessado em: 22/09/2020.

SILVA, Dhones S. N; MIRANDA, Marcelo H. G. de; SANTOS, Maria do Carmo G. Homofobia e Interseccionalidade: sentidos condensados a partir de uma pesquisa bibliográfica. In Revista Interritórios, v. 6, n. 10, p. 200-224, 2020.

SILVA, Mariah Rafaela. Código da ameaça: trans, Classe de risco: preta. N-1 edições, 2020. Disponível em: 〈https://n-1edicoes.org/123> Acessado em: 22/07/2020.

TAJRA, Alexa. Todos nós vamos morrer um dia: veja falas de Bolsonaro sobre o coronavírus. UOL, 2020. Disponível em: <https://noticias.uol.com.br/saude/ultimasnoticias/redacao/2020/05/01/todos-nos-vamos-morrer-um-dia-as-frases-de-bolsonaro-durantea-pandemia.htm> Acessado em: 22/07/2020.

TRANSEMPREGOS. TRANSformação: transformando vidas. Transempregos, 2020, Disponível em: $<$ https://www.transempregos.org/transformacao $>$. Acessado em: 22/07/2020.

UNIVERSIA. Escócia é $1^{\circ}$ país do mundo a incluir história LGBTQ+ no currículo escolar. Universia, 2020a. Disponível em: <https://www.uol.com.br/universa/noticias/ 
redacao/2020/06/12/escocia-e-1-pais-do-mundo-a-incluir-historia-lgbtq-no-curriculoescolar.htm> Acessado em: 22/07/2020.

Escolas de Seattle terão temas LGBTQ+ no currículo. Universia, 2020b. Disponível em: <https://www.uol.com.br/universa/noticias/redacao/2020/07/09/esco las-de-seattle-teraotemas-lgbtq-no-curriculo-e-banheiros-neutros.htm> Acessado em: 22/07/2020.

WHO Director-General's opening remarks at the media briefing on COVID-19 - 11 March 2020. World Health Organization, 2020. Disponível em:

$<$ https://www.who.int/dg/speeches/detail/who-director-general-s-opening-remarks-at-themedia-briefing-on-covid-19---11-march-2020>. Acessado em: 22/07/2020.

\#VOTELGBT. Diagnóstico LGBT+ na Pandemia. \#VoteLGBT, 2020. Disponível em: $<$ https://static1.squarespace.com/static/5b310b91af2096e89a5bc1f5/t/5ef78351fb8ae15cc0e0b

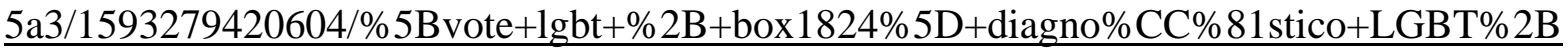
+na+pandemia_completo.pdf> Acessado em: 22/07/2020. 